\title{
Clinical guideline: febrile seizures, diagnosis and treatment
}

\author{
Carlos Aguirre-Velázquez ${ }^{1}$, Alma M. Huerta Hurtado², Hugo Ceja-Moreno ${ }^{3}$, Karina Salgado-Hernández ${ }^{4}$, \\ Roberto San Román-Tovar ${ }^{5}$, Martha A. Ortiz-Villalpando6, Avril Molina-García7, \\ Guadalupe Vargas-Ramírez ${ }^{8}$, Jaime López-Rivera ${ }^{9}$ and Rosana Huerta-Albarrán ${ }^{10}$
}

${ }^{1}$ Escuela Nacional de Medicina TEC de Monterrey, Monterrey; ${ }^{2}$ Hospital de Pediatría Centro Médico Nacional De Occidente IMSS, Guadalajara, Jalisco; ${ }^{3}$ Hospital Civil Viejo Fray Antonio Alcalde, Guadalajara, Jalisco; ${ }^{4}$ Hospital Materno Infantil ISSEMYM, Toluca; ${ }^{5} \mathrm{Hospital}$ General de Occidente Zoquipan, Zapopan, Jalisco; ${ }^{6}$ Centro de Rehabilitación Infantil e Inclusión Infantil de Occidente, CRIT, Guadalajara, Jalisco; ${ }^{7}$ Hospital Infantil de Especialidades de Chihuahua, Chihuahua; ${ }^{8}$ Hospital Pediátrico de León; León, Guanajuato; ${ }^{9}$ Hospital Universitario, Saltillo, Coahuila; ${ }^{10}$ Hospital General de México Dr. Eduardo Liceaga, Mexico City, Mexico

\begin{abstract}
Febrile seizures (FeS) are the most common problem in pediatric neurological practice. They are convulsive episodes during the course of febrile illness in the absence of epilepsy, severe hydroelectrolytic imbalance or neuroinfection. Its diagnosis is clinical and classified as simple and complex. Febrile status epilepticus occurs in approximately $5 \%$ of cases. It is convenient to teach parents how to act in a seizure and clarify that a FeS is not epilepsy, it is a benign process that usually does not leave neurological sequelae, and in which mortality is zero. In this clinical guide, we indicate risk factors for recurrence, management instructions for the first FeS, as well as criteria for hospital admission and treatment for prolonged seizures.
\end{abstract}

Key words: Febrile Seizures. Diagnosis. Treatment.

\section{What is a simple febrile seizure (SFeS)?}

SFeS happen in children 3-5 months old ${ }^{1-4}$. They are generalized tonic-clonic seizures accompanied by fever, without central nervous system (CNS) infection, metabolic disorder, or history of $\mathrm{FeS}^{5-8}$. Fever is considered as a rectal temperature greater than $38^{\circ} \mathrm{C}$, axillary temperature greater than $37.5^{\circ} \mathrm{C}$, or tympanic temperature greater than $38.2^{\circ} \mathrm{C}^{9}$. SFeS can occur before or after the fever becomes apparent, within $24 \mathrm{~h}$, during the course of a febrile illness ${ }^{10-12}$. SFeS affect $2-5 \%$ of the pediatric population and they are reported to be more frequent in some ethnic Asian groups ${ }^{3,13,14}$.
They are benign seizures, since they are induced convulsions and not related to epilepsy ${ }^{7,13}$.

\section{What is a complex FeS (CFeS)?}

A CFeS is a focal or generalized FeS lasting more than $15 \mathrm{~min}$, recurrent (more than once in $24 \mathrm{~h}$ ), and/or associated with postictal neurologic abnormalities, most commonly a postictal paralysis (Todd's paralysis), or when the patient presents with previous neurological impairment ${ }^{15-17}$.

The child that presents with a prolonged FeS which was interrupted with anticonvulsant therapy (such as
Available online: $12-04-2019$ Rev Mex Neuroci. 2019;20(2):97-103 www.revmexneurociencia.com 
Table 1. Lumbar puncture in FeS and criteria for hospitalization

Lumbar puncture must be obtained from children with FeS, younger than 12 months old,

who have not completed their immunizations or have received previous antibiotic treatment

Lumbar puncture must be obtained from children of any age with FeS that present with altered alertness and/or meningeal symptoms

Children younger than 6 months with a simple FeS must be punctured unless an experienced pediatrician evaluates the patient and declines, but he must reevaluate the patient in $2 \mathrm{~h}$

All patients under 18 months with their first simple FeS must be admitted to the emergency room.

Patients previously diagnosed with a recurrence of $\mathrm{FeS}$ do not require hospitalization

Hospitalization is not necessary in children older than 18 months that are clinically stable, without signs or symptoms that require diagnostic studies

III

I

I

I
C

A A

A

FeS: febrile seizures

diazepam [DZP]) before $15^{\text {th }}$ min must also be classified within this group ${ }^{15,18}$.

It is considered a febrile status epilepticus when a complex FeS lasts $>30 \mathrm{~min}$, or when there are shorter serial FeS without recovering consciousness during the interictal state ${ }^{6,10,15,16}$.

\section{When do you carry out a lumbar puncture in the first SFeS?}

In children of any age that have their first $\mathrm{FeS}$, it is important to discard an infection in the CNS (encephalitis/meningitis). Pay special attention when children are younger than 6 months, seizures last more than $15 \mathrm{~min}$, there are more than two seizures within a 24-h time period when there are focal motor or non-motor seizures with affected alertness, and/or when the child presents the following clinical data:

- Sleepiness alternating with irritability or Glasgow scale below 15 points.

- Neck stiffness, Kernig's sign, and Brudzinski's sign.

- Vomit, tense or bulging fontanelle, and papilledema.

- Presence of macular or petechial exanthem.

- Abnormal postures during the postictal state or if stupor remains for over an hour after a seizure 6,19-21.

The risk of bacterial meningitis in children that present with fever and seizures is about $3 \%$, but in a CFeS it is $9 \%$. Thus, lumbar puncture must be carried out in all children with CFeS and suspected CNS infection. In the case of CFeS without clinical signs of meningitis, they must be closely observed and checked after $2 \mathrm{~h}$ by a pediatrician to then decide again whether to carry out a lumbar puncture ${ }^{15}$ (Table 1).

\section{How are SFeS or CFeS treated during the acute ictal phase?}

Managing SFeS begins with training the parents for home management ${ }^{22}$ (Table 2). Informing the parents that their child will not die, that association with epilepsy is rare, and that the frequency of SFeS is reduced with age ${ }^{13,16,23,24}$. Warning them that if the seizure lasts 5 min or more, they must call an ambulance, provide emergent initial therapy, or go to the emergency room. Various authors support that intervention during the acute phase is rarely required ${ }^{12,28}$.

In the case of recurrent seizures, administer emergent initial therapy with the knowledge that the use of benzodiazepine may cause respiratory depression ${ }^{24}$. Benzodiazepine intravenous (IV), intramuscular, oral, intranasal, or rectal can be used to abort the crisis but is not recommended for prophylactic treatment ${ }^{1,25}$ (Table 3).

In a systematic review about the use of AEDs for ongoing convulsive seizures, including epileptic status, they analyzed the efficacy and safety of using Midazolam (MDL), DZP, lorazepam (LZP), phenytoin (PHT), phenobarbital (PB), and paraldehyde, concluding that IV or rectal LZP is as effective or more effective than DZP26. Oral MDL is more effective than rectal DZP, and the intranasal form is as effective as IV DZP. Oral or nasal MDL is the treatment of choice when there is no access to IV or for home management by the parents ${ }^{26-28}$ (Table 4). 
Table 2. Initial management of FeS at home ${ }^{22}$

1. Remain calm. Loosen clothes, especially around the neck. Protect the child from injury during the FeS

2. Do not introduce fingers or objects, or obstruct the mouth of the child. Do not force the mouth to open

3. Once the seizure has passed, make sure the child is in an adequate lateral position for recovery, where the airway is not obstructed

4. Observe the type of seizure or movement and its duration

5. Explain that after the seizure the child will be asleep for up to $1 \mathrm{~h}$

6. In the case of recurrent FeS, administer a emergent initial therapy drug if there is a tonic-clonic seizure that lasts $>5$ min

7. Administer oral or nasal midazolam as first-line treatment. Rectal diazepam $0.5 \mathrm{mg} / \mathrm{kg}$ when midazolam is not available

8. Seek medical attention if the seizure lasts $>5 \mathrm{~min}$. Contact your pediatrician or other health professional

9. The parents of children at high-risk for recurrence should receive the necessary training

FeS: febrile seizures

Table 3. Emergent initial therapy for acute (ictal) management of FeS in children ${ }^{25}$

\begin{tabular}{|l|l|l|}
\hline Antiepileptic & Administration route & Dose \\
\hline Midazolam (15mg/3 ml vial) & Oral & $0.5 \mathrm{mg} / \mathrm{kg}$, repeat in 10 min if necessary \\
& Nasal & $0.2-0.5 \mathrm{mg} / \mathrm{kg}$ divided in each nostril, maximum $10 \mathrm{mg}$ \\
& IV & $0.2 \mathrm{mg} / \mathrm{kg}$ or $0.15 \mathrm{mg} / \mathrm{kg}$ by infusion \\
& IM & $0.2 \mathrm{mg} / \mathrm{kg} \mathrm{or} 5-10 \mathrm{mg}$, sole dose \\
\hline Diazepam $(10 \mathrm{mg} / 3 \mathrm{ml}$ vial) & Rectal & $0.5 \mathrm{mg} / \mathrm{kg}$ \\
& IV & $0.3-0.5 \mathrm{mg} / \mathrm{kg}$, bolus speed of $5 \mathrm{mg} /$ minute, repeat in 10 min if necessary \\
\hline Lorazepam $(2 \mathrm{mg} / 3 \mathrm{ml}$ vial) & IV & $0.01 \mathrm{mg} / \mathrm{kg} / \mathrm{min}$ by infusion \\
\hline
\end{tabular}

IV: intravenous, IM: intramuscular, Oral Midazolam is more effective than rectal Diazepam, and the intranasal route is equally effective as IV diazepam (Level I evidence), Oral or nasal Midazolam is the treatment of choice when there is no access to IV or for home management by the parents (Level III evidence), FeS: febrile seizures

Table 4. SF treatment in a hospital environment

\begin{tabular}{|l|l|}
\hline 1 & Assess A, B, C \\
\hline 2 & Open the airway, aspirate secretions, maintain adequate ventilation, and ensure perfusion \\
\hline 3 & Obtain venous access \\
\hline 4 & Monitor vital signs (heart rate, respiratory rate, arterial pressure, and pulse oximetry) \\
\hline 5 & Administer oxygen, if necessary (Sa02 $<90 \%$ ) \\
\hline 6 & $\begin{array}{l}\text { Administer an intravenous bolus of Diazepam at a dose of } 0.5 \mathrm{mg} / \mathrm{kg} \text { and a maximum infusion speed of } 5 \mathrm{mg} / \mathrm{min}, \\
\text { discontinue when the seizure stops. The dose can be repeated, if necessary, after an interval of } 10 \mathrm{~min} \text { (consider that } \\
\text { Diazepam takes about } 10 \mathrm{~m} \text { to reach an effective concentration in the brain, even using intravenous administration). Other } \\
\text { benzodiazepines, like Lorazepam, are equally effective }\end{array}$ \\
\hline 7 & $\begin{array}{l}\text { Monitor excess base and glucose in blood } \\
\text { If the convulsion does not subside, ask for advice from a specialist to determine treatment }\end{array}$ \\
\hline 8 & $\begin{array}{l}\text { The Febrile Status Epilepticus must be treated under the same treatment considerations as pediatric Afebrile Status } \\
\text { Epilepticus }\end{array}$ \\
\hline 9 & $\begin{array}{l}\text { The measures taken for fever reduction must begin after benzodiazepine administration, as long as it does not interfere } \\
\text { with routine attention }\end{array}$ \\
\hline 10 &
\end{tabular}




\section{Hospitalization criteria}

Independently of the length of the seizure, the patient must be assessed by medical history, documentation of SFeS history, epilepsy, immunizations, duration of the seizure, postictal phase, and any focal symptom ${ }^{4}$. The American Academy of Pediatrics recommends that hospitalization is unnecessary for clinically stable patients older than 18 months, without signs or symptoms that require diagnostic studies ${ }^{29}$. Parents are trained for home management (Table 1) ${ }^{22}$. Hospitalization recommended for children younger than 18 months, for observation and possible lumbar puncture. Patients previously diagnosed with recurrent $\mathrm{FeS}$ do not require hospitalization $^{12,29}$ (Table 1).

\section{Is long-term antiepileptic treatment required for FeS?}

\section{Simple FeS, SFeS}

A systematic review that assesses the use of conservative and antipyretic measures concluded that there is no evidence that they have any usefulness in preventing SFeS reccurences ${ }^{30}$. There is no evidence for the clinical usefulness of continuous or intermittent use of antiepileptic drugs (oral or rectal DZP, PB, diphenylhydantoin, or valproate) in $\mathrm{SFeS}^{23}$. There is no evidence that continuous or intermittent treatment with antiepileptic drugs in SFeS can prevent the subsequent development of epilepsy $6,18,31$.

\section{Complex FeS CFeS}

Long-term routine prophylaxis with antiepileptic drugs is not recommended since there is no clear information about their use in complex $\mathrm{FeS}^{23}$. There is evidence that supports intermittent use of PB and antipyretics, clobazam, or rectal DZP, to prevent recurrence of complex FeS. However, the information does not clearly distinguish simple from complex seizures, and there may be bias due to the relative incidence of both types of seizures ${ }^{32}$.

Regular use of antiepileptic drugs can be considered for patients with long or repetitive FeS despite the prophylactic use of DZP ${ }^{33}$. Carbamazepine and PHT are not effective for preventing the recurrence of $\mathrm{FeS}$ and thus, should be avoided ${ }^{24}$.

A prospective study, carried out in 2014 , compared the efficacy of intermittent use of clobazam versus DZP to prevent recurrence of $\mathrm{FeS}$ (both simple and complex), as well as the adverse effects. The results showed that clobazam is safe, effective, requires a lower dose, and has fewer adverse effects than DZP, suggesting it as a good alternative for preventing recurrence of $\mathrm{FeS}^{34}$. In addition, in 2017, another group demonstrated a significant difference in the prevention of recurrence after treatment with levetiracetam versus no treatment after 50 weeks $^{14}$ Table 5.

\section{What paraclinical tests are necessary after the first FeS?}

Diagnostic tests (analytic, electroencephalogram (EEG), and cerebral imaging) are usually unnecessary and, currently, are not routinely recommended for patients with simple $\mathrm{FeS}^{15,17}$.

\section{Electroencephalogram}

Not indicated for the assessment of a neurologically healthy child with simple $\mathrm{FeS}^{6}$. In a focal and/or prolonged convulsion, it is recommended to carry out an EEG and neurologic follow-up, due to the greater risk of developing epilepsy. A short, generalized convulsion that is repeated twice in $24 \mathrm{~h}$ is, by definition, a complex convulsion, but it is also not necessary to conduct an EEG unless the neurologic examination shows alterations.

The EEG does not allow prediction of which children are at greater risk to suffer new seizures. Epileptiform alterations in the EEG are relatively frequent in children with FeS. Few retrospective, cohort, case and control studies show a possible association between the epileptiform discharges in the EEG and a high risk of afebrile/epileptic seizures ${ }^{35}$. The EEG has low sensitivity in children under 3 years of age, after an unprovoked convulsion ${ }^{35-37}$.

\section{Laboratory tests}

They can be considered under certain clinical conditions but are not routinely carried out in a child after his first FeS with an evident source of infection. They will only identify the source of the child's fever and are not necessary as part of the assessment of the seizure ${ }^{6,17}$.

\section{Neuroimaging}

Highly recommended for patients with FeS that do not regain complete consciousness in hours, with prolonged Todd's paralysis (post-critical), or with other 
Table 5. Long-term treatment for simple FeS and Complex SF

\begin{tabular}{l|l|l|}
\hline Data & Level of Evidence & Recommendation \\
\hline $\begin{array}{l}\text { Intermittent antipyretics, zinc, pyridoxin, or antiepileptic drugs are not useful for the } \\
\text { prevention of recurrences of FeS }\end{array}$ & A \\
\hline $\begin{array}{l}\text { The continuous or intermittent use of antiepileptic drugs, such as DZP, PHT, PB, or VPA, } \\
\text { is not useful }\end{array}$ & I \\
\hline $\begin{array}{l}\text { The continuous or intermittent use of antiepileptic drugs in FeS does not prevent the } \\
\text { subsequent development of epilepsy }\end{array}$ & I & A \\
\hline $\begin{array}{l}\text { The regular use of antiepileptic drugs can be considered for patients with prolonged or } \\
\text { repeated FeS despite the prophylactic use of diazepam }\end{array}$ & I, II \\
\hline $\begin{array}{l}\text { Levetiracetam could work as an antiepileptic drug for prevention of recurrence of FeS } \\
\text { Clobazam is safe, effective and requires a lower dose than diazepam }\end{array}$ & III \\
\hline $\begin{array}{l}\text { Carbamazepine and phenytoin are not effective for the prevention of recurrence of FeS } \\
\text { and should be avoided }\end{array}$ & II \\
\hline $\begin{array}{l}\text { Children with FeS should receive the complete recommended immunization program for } \\
\text { their age }\end{array}$ & I \\
\hline
\end{tabular}

FeS: febrile seizures, DZP: diazepam, PHT: phenytoin, PB: phenobarbital

Table 6. Indications to carry out paraclinical tests in FeS

\begin{tabular}{|l|l|l|}
\hline Data & Evidence level & Recommendation \\
\hline $\begin{array}{l}\text { Conducting analytic tests routinely (CBC, blood glucose, electrolytes, calcium, and } \\
\text { magnesium), are not useful for the management of children with FeS }\end{array}$ & III \\
\hline $\begin{array}{l}\text { Routine cerebral imaging tests are not recommended for children with SFeS or CFeS. } \\
\begin{array}{l}\text { Neuroimaging is indicated for patients that do not regain complete consciousness in } \\
\text { hours, with prolonged Todd's paralysis (post-critical), or other focal alterations found in } \\
\text { the neurologic exploration }\end{array}\end{array}$ & II-III & C \\
\hline Routine EEG is not recommended for children with SFeS & II & B \\
\hline EEG in the case of focal FeS to discard seizures unleashed by fever & III & R-PPE
\end{tabular}

FeS: febrile seizure, SFeS: simple febrile seizure

focal alterations found in the neurologic exploration ${ }^{15,16}$ (Table 6).

\section{What are the risk and recurrence factors for SFeS and CFeS?}

Population risk of a FeS is $2.7-3.1 \%{ }^{36}$. The reported risk of recurrence after a first FeS is $27-32 \%$ of which $75 \%$ happen during the $1^{\text {st }}$ year after the first crisis ${ }^{18}$. The risk of recurrence is similar between simple and complex $\mathrm{FeS}^{38}$. The risk factors for FeS are enlisted in Table 7. The frequency of recurrence is $10 \%$ among patients with no risk factors; $25-50 \%$ in the presence of $1-2$ risk factors; and $50-100 \%$ when there are three or more risk factors ${ }^{15}$. The risk of developing epilepsy after a SFeS is 1.5-2.4\% while for complex FeS it is estimated to be $4-15 \%{ }^{39}$, and in the case of focal FeS up to $29 \% 40$.

\section{When should cases of SFeS and CFeS be referred to the neuropediatrician?}

FeS is a benign condition; they are not associated with neurodevelopmental damage nor do they cause secondary neurologic consequences ${ }^{6}$. The only association found was between repeated FeS and a delay in language development; thus, new studies and longer-term follow-up will be required ${ }^{42}$. Hippocampal malformations do not appear to be a consequence of FeS but can be a predisposing factor for the development 
Table 7. FeS risk factors ${ }^{15,35,41}$

\section{Recurrence after an initial FeS}

Early onset (<12 months)

Epilepsy in first-grade family members

FeS in first-grade family members

Frequent febrile illnesses
Factors for developing epilepsy

Age during the first FeS: $<12$ months or $>37$ months

Family history of epilepsy

Fever lasting $<1 \mathrm{~h}$ before the seizure

Temperature in the lower range of fever at the moment of the FeS

Fever lasting $<1 \mathrm{~h}$ before the seizure.

Low Apgar at $5 \mathrm{~min}$

History of at least $1 \mathrm{CFeS}$

Febrile status epilepticus

Multiple seizures in $24 \mathrm{~h}$

Focal seizures

Neurologic abnormalities (retarded development or CCP)

Focal epileptogenic discharges

CFeS: complex febrile seizure, FeS: febrile seizure

of epilepsy ${ }^{7}$. Providing the family with information about the illness and the risk of recurrence during the illness or in the future should be carried out by the pediatrician. However, if the clinical history shows $>2$ risk factors of seizure recurrence or the patient fulfills the requirements for complex FeS, we recommend he be referred to the neuropediatrician.

\section{Conclusion}

FeS is an age-dependent phenomenon, related to individual genetic predisposition and with a special vulnerability of the developing CNS to the effects of fever. The continued or intermittent prophylactic treatment with antiepileptic drugs does not reduce the risk of subsequent epilepsy and, although it is effective to reduce recurrences, its toxicity surpasses the few risks of FeS.

Informed and responsible parental counseling are the greatest contribution that the physician can make for the care of children with FeS.

\section{References}

1. Pavone $\mathrm{P}$, Corsello $\mathrm{G}$, Ruggieri $\mathrm{M}$, et al. Benign and severe early-life seizures: a round in the first year of life. Ital J Pediatr. 2018;44:54.

2. Takasu M, Kubota T, Tsuji T, et al. The semiology of febrile seizures: focal features are frequent. Epilepsy Behav. 2017;73:59-63.

3. Martínez C, Herráiz-Martínez M. Crisis febriles complejas: debemos cambiar nuestro modo de actuación? Rev Neurol. 2014;59:449-58.

4. Chung S. Febrile seizures. Korean J Pediatr. 2014:57:384-95.
5. Auvin S, Antonios M, Benoist G, et al. Evaluating a child after a febrile seizure: insights on three important issues. Arch Pediatr. 2017;24: 1137-46

6. American Academy of Pediatrics. Clinical practice guideline. Febrile seizures: guideline for the neurodiagnostic evaluation of the child with a simple febrile seizure. Pediatrics. 2011;127:389-94

7. Frascari F, Dreyfus I, Chaix Y, Tison-Chambellan C. Efficacy of an interventional educational programme in mitigating posttraumatic stress in parents who have witnessed a febrile seizure: a pilot before-and-after study. BMJ Paediatr Open. 2017;12:1-6.

8. Assogba K, Balaka B, Touglo FA, Apetsè KM, Kombaté D. Febrile seizures in one-five aged infants in tropical practice: frequency, etiology and outcome of hospitalization. J Pediatr Neurosci. 2015;10:9-12.

9. Guía de Practica Clínica: diagnóstico y Tratamiento de la Fiebre en Niños de 3 Meses a 5 Años. CENETEC; 2013.

10. Moreno N. Crisis febriles simples y complejas, epilepsia generalizada con crisis febriles plus, FIRES y nuevos síndromes. Medicina. 2013;73: 63-70.

11. Zeballos J, Cerisola A, Pérez W. Primera convulsión febril en niños asistidos en un servicio de emergencia pediátrica. Arch Pediatr Urug. 2013;84:18-25.

12. Gupta A. Febrile seizures. Continuum (Minneap Minn). 2016;22:51-9.

13. Byeon JH, Kim GH, Eun BL. Prevalence, incidence, and recurrence of febrile seizures in Korean children based on national registry data. J Clin Neurol. 2018;14:43-7.

14. Li XC, Lu LL, Wang JZ, et al. Clinical characteristics and electroencephalogram analysis of levetiracetam in the treatment of children with febrile seizure recurrence. Exp Ther Med. 2017:14:2015-20.

15. Capovilla G, Mastrangelo M, Romeo A, Vigevano F. Recommendations for the management of "febrile seizures": ad hoc task force of LICE guidelines commission. Epilepsia. 2009:50 Suppl 1:2-6.

16. Blanco M, Gascón J. Evaluación y Tratamiento de las Convulsiones Febriles. en: guía de la Sociedad Andaluza de Epilepsia; 2015. p. 161-70.

17. López RB, Fernández JM, Antón JM, Fernández MG, Cardona AU. Complex febrile seizures: study of the associated pathology and practical use of complementary tests. An Pediatr (Barc). 2014;80:365-9.

18. Knudsen FU. Febrile seizures: treatment and prognosis. Epilepsia. 2000;41:2-9

19. Sugai K. Current management of febrile seizures in Japan: an overview. Brain Dev. 2010;32:64-70.

20. Kimia AA, Ben-Joseph E, Prabhu S, et al. Yield of emergent neuroimaging among children presenting with a first complex febrile seizure. $\mathrm{Pe}$ diatr Emerg Care. 2012;28:316-21.

21. Shaked O, Peña BM, Linares MY, Baker RL. Simple febrile seizures: are the AAP guidelines regarding lumbar puncture being followed? Pediatr Emerg Care. 2009;25:8-11. 
22. Silverman EC, Sporer KA, Lemieux JM, et al. Prehospital care for the adult and pediatric seizure patient: current evidence-based recommendations. West J Emerg Med. 2017;18:419-36.

23. Offringa $M$, Newton R. Prophylactic drug management for febrile seizures in children. Evid Based Child Health. 2013;8:1376-485.

24. Patel $A D$, Vidaurre J. Complex febrile seizures: a practical guide to evaluation and treatment. J Child Neurol. 2013;28:762-7.

25. Zhao ZY, Wang HY, Wen B, et al. A comparison of midazolam, lorazepam, and diazepam for the treatment of status epilepticus in children: a network meta-analysis. J Child Neurol. 2016;31:1093-107.

26. McTague A, Martland T, Appleton R. Drug management for acute tonic-clonic convulsions including convulsive status epilepticus in children. Cochrane Database Syst. Rev 2018;1:CD001905.

27. Mewasingh LD. Febrile seizures. BMJ Clin Evid. 2014;2014:324.

28. Sirsi D. Is intranasal midazolam better than rectal diazepam for home management of acute seizures? Arch Neurol. 2011;68:120-1.

29. American Academy of Pediatrics. Provisional committee on quality improvement, subcommittee on febrile seizures. Practice parameter: the neurodiagnostic evaluation of the child with a first simple febrile seizure. Pediatrics. 1996;97:769-75.

30. Rosenbloom E, Finkelstein Y, Adams-Webber T, Kozer E. Do antipyretics prevent the recurrence of febrile seizures in children? A systematic review of randomized controlled trials and meta-analysis. Eur J Paediatr Neurol. 2013;17:585-8.

31. Baumann RJ, Duffner PK. Treatment of children with simple febrile seizures: the AAP practice parameter. American academy of pediatrics. Pediatr Neurol. 2000;23:11-7.
32. Salehiomran M, Hoseini SM, Juibary AG. Intermittent diazepam versus continuous phenobarbital to prevent recurrence of febrile seizures: a randomized controlled trial. Iran J Child Neurol. 2016;10:21-4.

33. Natsume J, Hamano SI, lyoda K, et al. New guidelines for management of febrile seizures in Japan. Brain Dev. 2017;39:2-9.

34. Sattar S, Saha SK, Parveen F, et al. Intermittent prophylaxis of recurrent febrile seizures with clobazam versus diazepam. Mymensingh Med J. 2014;23:676-85.

35. Cappellari AM, Brizio C, Mazzoni MB, et al. Predictive value of EEG for febrile seizure recurrence. Brain Dev. 2018;40:311-5.

36. Armon K, Stephenson T, MacFaul R, et al. An evidence and consensus based guideline for the management of a child after a seizure. Emerg Med J. 2003;20:13-20.

37. Harini $C$, Nagarajan E, Kimia AA, et al. Utility of initial EEG in first complex febrile seizure. Epilepsy Behav. 2015;52:200-4.

38. Graves R, Oehler K. Febrile seizures: risks, evaluation, and prognosis. Am Fam Phys. 2012;85:149-53.

39. Gencpinar P, Yavuz H, Bozkurt Ö, Haspolat $\otimes$, Duman Ö. The risk of subsequent epilepsy in children with febrile seizure after 5 years of age. Seizure. 2017;53:62-5

40. Pavlidou E, Panteliadis C. Prognostic factors for subsequent epilepsy in children with febrile seizures. Epilepsia. 2013;54:2101-7.

41. Olson H, Rudloe T, Loddenkemper T, Harper MB, Kimia AA. Should patients with complex febrile seizure be admitted for further management? Am J Emerg Med. 2018;36:1386-90.

42. Visser AM, Jaddoe VW, Ghassabian A, et al. Febrile seizures and behavioural and cognitive outcomes in preschool children: the generation $R$ study. Dev Med Child Neurol. 2012;54:1006-11. 